\title{
EFEKTIVITAS PENGEMBANGAN BAHAN AJAR BERBASIS BUKU CERITA DI ERA NEW NORMAL PADA MATA PELAJARAN SKI TEMA MENELADANI PERJUANGAN DAKWAH RASULULLAH SAW. DI MADINAH
}

\begin{abstract}
Oleh:

${ }^{1}$ Moh. Hafid

${ }^{2}$ Agus Fauzi

Email: Situbondo

This research aimed to determine the effectiveness of immplementation teaching material based buk u cerita on the Islamic culture history subject with theme the imitating the prophet Muhammad's dakwah struggle in Madina in the new normal era. The subjects of this study were students of grade $10^{\text {th }}$ in Argayasa Islamic Senior High School. This study uses experimental research methods with the research design used postest only control design. Test instrument was given to student is multiple choice questions consisting of 10 questions. Data analyses uses different test mannwhitney in nonparametric statistic. The result showed that average value of experimental and control classes, respectively 35,62 and 13,38. Furthermore, using mann-whitney that shows the value of Asymp. Sig. (2-tailed) is 0,000. So that there is significantly effect by a treatment of learning material based storybook to student learning achievement on the Islamic culture bistory subject with theme the imitating the prophet Mubammad's dakwah struggle in Madina. So, learning material based storybook is effective used on the Islamic culture bistory subject with theme the imitating the prophet Muhammad's dakwah struggle in Madina.
\end{abstract}

1 innovation.hafid@gmail.com

1 agusfauzie27@gmail.com

${ }^{1}$ Universitas Ibrahimy,

2 PPs. STAI Ma'had Aly Al-Hikam, Malang
Keywords: Effectiveness, Buku cerita, Islamic culture bistory

\section{PENDAHULUAN}

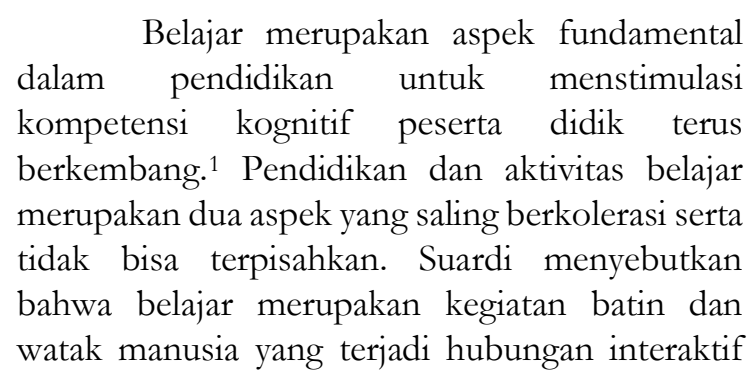

${ }^{1}$ Moh. Nawafil and Junaidi Junaidi, "Revitalisasi Paradigma Baru Dunia Pembelajaran Yang Membebaskan," Jurnal Pendidikan Islam Indonesia 4, no. 2 (April 15, 2020): 215-25, doi:10.35316/jpii.v4i2.193.

2 M Suardi, Belajar Dan Pembelajaran (Yogyakarta: CV Budi Utama, 2015), 50. dengan lingkungannya sehingga menciptakan pengetahuan dan pemahaman baru yang relatif menetap. $^{2}$ Untuk menciptakan kegiatan pembelajaran yang berdaya guna, maka hadirnya strategi pembelajaran sangat urgen diciptakan. Strategi pembelajaran yang baik dapat tercipta oleh sosok pendidik yang kreatif. Sehingga guru yang mempunyai banyak inovasi berdampak pada motivasi belajar peserta didik yang tinggi. ${ }^{3}$
${ }^{3}$ Rati Purwanto, "Home Visit Method Dalam Upaya Meningkatkan Motivasi Belajar Siswa Sekolah Dasar," Terampil: Jurnal Pendidikan Dan Pembelajaran Dasar 8, no. 1 (2021): 51-64. 
Penerapan strategi pembelajaran yang tepat guna salah satunya ialah dengan memaksimalkan alat, bahan, media dan unsurunsur penting lainnya disekitar pendidik untuk dimanfaatkan dengan baik. ${ }^{4}$ Penggunaan bahan ajar bisa memberikan peluang bagi peserta didik supaya belajar independen yang didalamnya tetap terdapat berbagai petunjuk dari guru sehingga siswa juga bisa memilih waktu belajar yang disenanginya. ${ }^{5}$ Widodo dan Jasmadi berpendapat bahwa bahan ajar ialah sekelompok bahan yang berisikan materi ajar dengan maksud untuk menguasai target pembelajaran secara mudah. ${ }^{6}$ oleh karenanya, bahan ajar memang didesain bagi siswa untuk memahami materi ajar dengan mudah.

Bahan ajar mempunyai fungsi sebagai panduan bagi peserta didik dalam mengarahkan segala aktivitas belajarnya dan esensi kompetensi yang harus dikuasai atau dicapai. ${ }^{7}$ Bagi guru, bahan ajar berfungsi sebagai esensi kemampuan peserta didik yang harus dibimbing dan diajarkan kepada peserta didik. ${ }^{8}$ Tidak hanya itu saja, bahan ajar juga berfungsi sebagai penentu keberhasilan belajar peserta didik. ${ }^{9}$ berbagai fungsi bahan ajar yang banyak memiliki unsur manfaat, maka seyogianya pendidik mempunyai kompetensi dalam mengembangkan bahan ajar yang baik. Sehingga ketercapaian tujuan pembelajaran bisa diperoleh secara maksimal.

Pengembangan bahan ajar, salah satunya telah diprakarsai oleh Bapak Ading selaku kepala sekolah sekaligus pendidik yang mengampu mata pelajaran sejarah kebudayaan Islam. Berdasarkan data hasil wawancara dengan Bapak Ading, bahwa bahan ajar yang dikembangkan berupa buku cerita yang telah terintegerasi dengan materi pelajaran sejarah kebudayaan Islam tema "Meneladani Perjuangan Dakwah Rasulullah Saw di Madinah." Bahan ajar berbasis buku cerita tersebut juga

\footnotetext{
4 Tejo Nurseto, "Membuat Media Pembelajaran Yang Menarik," Jurnal Ekonomi \& Pendidikan 8, no. 1 (2011): 1935.

5 M Atwi Suparman, Desain Instruksional Modern (Jakarta: Erlangga, 2014), 312

${ }^{6}$ Chomsin S Widodo and Jasmadi, Panduan Menyusun Baban Ajar Berbasis Kompetensi (Jakarta: Elex Media Komputindo, 2008), 48.

7 Umi Khulsum, Yusak Hudiyono, and Endang Dwi Sulistyowati, "Pengembangan Bahan Ajar Menulis Cerpen Dengan Media Storyboard Pada Siswa Kelas X SMA," DIGLOSLA : Jurnal Kajian Bahasa, Sastra, Dan Pengajarannya 1, no. 1 (2018): 1-12, doi:10.30872/diglosia.v1i1.pp1-12.

8 Fitri Erning Kurniawati, "Pengembangan Bahan Ajar Aqidah Ahklak Di Madrasah Ibtidaiyah," Jurnal Penelitian 9, no. 2 (2015): 367, doi:10.21043/jupe.v9i2.1326.
}

memuat kisah keteladanan para ulama yang ditujukan agar peserta didik tidak bosan membacanya. Latar tempat dari alur cerita tersebut didesain dalam dua aspek, yakni lingkungan sekitar dan sekolah. Materi pembelajaran tentang "Meneladani Perjuangan Dakwah Rasulullah Saw di Madinah" dipadukan dengan cerita keteladanan para ulama menggunakan bahasa yang bersahabat bagi peserta didik.

Buku cerita diartikan sebagai rangkaian cerita yang terlukis dalam dunia insan dan benda yang terdapat disekeliling kita, tidak implisit, lebih dominan menggambarkan satu periode dari keadaan seorang insan, dan sering menyentuh pada suatu peristiwa. ${ }^{10} \mathrm{Di}$ Indonesia ada beberapa macam buku cerita yang familiar. Diantaranya ialah buku cerita yang terkandung dalam novel. Pada biasanya hamper seluruh novel yang ada pasti bermuatan cerita, sebab tujuan utama dalam buku novel ialah untuk memuaskan para pembaca. Terdapat dua macam novel yakni novel serius dan novel popular. Novel popular seringkali ditujukan pada hal-hal yang bersangkutpaut dengan bisnis, kesenangan orang yang membaca, sehingga novel popular biasanya tidak menjelaskan pada suatu hal yang sifatnya serius sebab yang akan terjadi ialah merosotnya penikmat novel tersebut. Umumnya novel ini relatif gampang dibaca dan tidak susah dipahami karena dalam novel tersebut bermuatan cerita. ${ }^{11}$

Penelitian terhadap efektifitas bahan ajar juga pernah dilakukan oleh peneliti-peneliti lain sebelumnya, diantaranya ialah M. Khoiri dan Kusyairi dalam penelitiannya yang berjudul Penilaian Bahan Ajar Bahasa Madura Tingkat Sekolah Menengah Atas (SMA) dengan hasil bahwa bahan ajar dapat digunakan dengan kategori valid $70,64 .^{12}$ Yunita Sari dan Sari Yustiana dalam penelitiannya yang berjudul

\footnotetext{
${ }^{9}$ Kartika Permata Sari, "Evaluasi Bahan Ajar Bahasa Prancis Le Mag Sebagai Bahan Pembelajaran Mandiri Siswa Sekolah Menengah Atas," Jurnal Inovasi Teknologi Pendidikan 4, no. 2 (2018): 214-26, doi:10.21831/jitp.v4i2.17155.

10 Tim Universitas Gajah Mada, Teori Pengkajian Fiksi (Yogyakarta: Gajah Mada University Press, 2010), 9.

11 Endang Sri Sulasih, "Pengaruh Minat Membaca Karya Sastra Dan Kreativitas Terhadap Keterampilan Menulis Buku cerita," Pujangga 2, no. 2 (2018): 24, doi:10.47313/pujangga.v2i2.392.

${ }^{12}$ M. Khoiri and Kusyairi, "Penilaian Bahan Ajar Bahasa Madura Tingkat Sekolah Menengah Atas (SMA)," Jurnal Babasa, Sastra Indonesia, Dan Pengajarannya 2, no. 2 (2019): 274-285.
} 
Efektivitas Bahan Ajar Cerita Bergambar Bemuatan Religius Terhadap Prestasi Belajar Siswa Kelas 1 Sekolah Dasar menghasilkan temuan bahwa bahan ajar berbasis cerita bergambar memperoleh nilai sebesar 0,53 dengan kategori sedang yang bermakna efektif terhadap prestasi belajar siswa. ${ }^{13}$ Penelitian lain juga dilakukan oleh Sri Handayani dalam jurnal ilmiahnya yang berjudul Perbandingan Efektifitas Pemberian Informasi Melalui Media Cerita Bergambar (Komik) Versi BKKBN dengan Media Leaflet menghasilkan temuan bahwa pada ranah kognitif, media komik dapat meningkatkan pengetahuan tiga kali dibandingkan leaflet, sedangkan pada ranah afektif, media komik mempunyai peningkatan empat kali dibandingkan leaflet. Jadi kesimpulan dari penelitian Sri Handayani ialah efektifitas media yang terintegerasi dengan cerita bergambar lebih tinggi dari pada media leaflet dalam mensurpluskan kompetensi kognitif dan afektif remaja tentang life style yang sehat. ${ }^{14}$

Bahan ajar berbasis buku cerita yang mengintegerasikan materi sejarah kebudayaan Islam tema meneladani perjuangan dakwah Rasulullah Saw di Madinah dengan kisah keteladanan para ulama yang diterapkan di Madrasah Aliyah Argayasa pada era new normal mempunyai keunggulan tersendiri. Sebagaimana yang diungkapkan oleh kepala sekolah bahwa bahan ajar berbasis buku cerita dapat membangkitkan motivasi siswa membaca materi pelajaran di rumah. Sebab siswa juga tertarik dengan cerita yang digambarkan dalam buku cerita tersebut dan berusaha mengetahui beberapa keteladanan para ulama. Di samping iru, proses kegiatan pembelajaran yang dilakukan oleh pendidik pada era new normal terbatas oleh waktu yang tidak maksimal sebagaimana aktivitas pembelajaran sebelum adanya COVID-19. ${ }^{15}$

Dari paparan data di atas, peneliti tertarik untuk menguji seberapa efektifkah penerapan bahan ajar berbasis buku cerita terhadap hasil belajar siswa di Madrasah Aliyah Argayasa pada era new normal. Adapun hipotesis dalam penelitian ini ialah $\mathrm{H}_{\mathrm{o}}$ : tidak terdapat perbedaan hasil belajar siswa kelas X IPS 1 yang menggunakan bahan ajar berbasis buku cerita dengan kelas X IPS 2 yang

13 Yunita Sari and Sari Yustiana, "Efektivitas Bahan Ajar Cerita Bergambar Bemuatan Religius Terhadap Prestasi Belajar Siswa Kelas 1 Sekolah Dasar," Jurnal Ilmiah Pendidikan Dasar 8, no. 2 (2021): 175, doi:10.30659/pendas.8.2.175-185. 14 Sri Handayani, "Perbandingan Efektifitas Pemberian Informasi Melalui Media Cerita Bergambar (Komik) Versi menggunakan bahan ajar dari sekolah, $\mathrm{H}_{\mathrm{a}}$ terdapat perbedaan hasil belajar siswa kelas X IPS 1 yang memakai bahan ajar berbasis buku cerita dengan kelas X IPS 2 yang menggunakan bahan ajar dari sekolah.

\section{Perumusan Masalah}

Dari uraian pendahuluan di atas, maka dirumuskan pertanyaan penelitian pada tahap ini ialah sebagai berikut:

1. Bagaimanakah efektivitas penerapan produk pengembangan bahan ajar berbasis buku cerita pada mata pelajaran sejarah kebudayaan Islam tema meneladani perjuangan dakwah Rasulullah Saw di Madinah Pada Era New Normal?

\section{Tujuan Pembahasan}

Adapun tujuan pembahasan dalam penelitian ini ialah untuk :

1. Mengetahui efektivitas penerapan produk pengembangan bahan ajar berbasis buku cerita pada mata pelajaran sejarah kebudayaan Islam tema meneladani perjuangan dakwah Rasulullah Saw di Madinah Pada Era New Normal

\section{Metode Penelitian}

Populasi dalam riset ini ialah seluruh siswa kelas X di Madrasah Aliyah Argayasa. Teknik menentukan sampel dalam penelitian ini menggunakan purposive sampling. Adapun sampel dalam penelitian ini ialah kelas X IPS 1, kelas X IPS 2 dan kelas X IPS 3. Kelompok eksperimen diberlakukan pada kelas X IPS 1 dan kelompok kontrol diberlakukan pada kelas X IPS 2. Adapun kelas $\mathrm{X}$ IPS 3 diberlakukan untuk menguji validitas dan reliabilitas instrument tes. Desain penelitian yang digunakan ialah true experimental design dengan bentuk postest only control design. Eksperimen ditujukan untuk menemukan eksistensi sebuah pengaruh dari diterapkannya treatment. Metode eksperimen dalam riset ini bertujuan untuk mengetahui pengaruh dari bahan ajar berbasis buku cerita pada kelas eksperimen dan bahan ajar dari sekolah pada kelas kontrol. Sebagaimana layaknya penelitian eksperimen, dalam penelitian ini melibatkan kelas X IPS 1

BKKBN Dengan Media Leaflet," GASTER 7, no. 1 (2010): 482-90.

${ }^{15}$ Muh. Shaleh and La Ode Anhusadar, "Kesiapan Lembaga PAUD Dalam Pembelajaran Tatap Muka Pada New Normal," Jurnal Obsesi: Jurnal Pendidikan Anak Usia Dini 5, no. 2 (2021): 2158-67. 
sebagai kelas eksperimen dan kelas X IPS 2 sebagai kelas kontrol. Kelas X IPS 1 diberi treatment bahan ajar berbasis buku cerita sedangkan kelas X IPS 2 tidak diberi perlakuan. Teknik pengumpulan data pada penelitian ini menggunakan teknik tes. Product moment digunakan untuk menganalisis instrumen tes sehingga dapat diketahui validitas instrumen. Alpha cronbach's digunakan untuk menganalisis instrumen tes sehingga dapat diketahui reliabilitas instrument. Hasil data penelitian dianalisis melalui mann-whitney untuk menginterpretasikan kesimpulan riset.

\section{Kerangka Konseptual}

\section{Pengembangan Bahan Ajar}

Pengembangan bahan ajar merupakan salah satu upaya dalam menciptakan inovasi produk dalam pembelajaran yang ditujukan untuk memfasilitasi belajar siswa supaya lebih mudah memahami materi. Bahan ajar juga sangat dibutuhkan oleh guru untuk pendamping siswa dalam belajar. Bahan ajar adalah segala bentuk bahan yang digunakan untuk membantu guru atau instruktur dalam melaksanakan proses pembelajaran di kelas menurut National Centre for Competency Based Training. ${ }^{16}$ Pandangan dari ahli lainya mengatakan bahwa bahan ajar adalah seperangkat materi yang disusun secara sistematis, baik tertulis maupun tidak tertulis, sehingga tercipta lingkungan atau susasana yang memungkinkan peserta didik untuk belajar.

Guru harus memilih bahan ajar yang sesuai dengan kurikulum, karakteristik sasaran, dan tuntutan pemecahan masalah belajar. Bahan ajar yang dikembangkan oleh guru pasti mengharapkan tujuan dan manfaatnya baik bagi guru itu sendiri maupun siswanya. Berikut ini penjelasan tujuan dan manfaat bahan ajar ${ }^{17}: 1$ ) menyediakan bahan ajar yang sesuai dengan tuntutan kurikulum dengan mempertimbangkan kebutuhan peserta didik, yakni bahan ajar yang sesuai dengan karakteristik dan setting atau lingkungan sosial siswa; 2) manfaat bahan ajar bagi guru yaitu diperoleh bahan ajar yang sesuai tuntutan kurikulum dan sesuai dengan kebutuhan belajar siswa, tidak lagi tergantung kepada buku teks yang terkadang sulit diperoleh, memperkaya karena dikembangkan dengan menggunakan berbagai referensi, menambah khasanah pengetahuan dan pengalaman guru dalam menuli

16 A Praswoto, Panduan Kreatif Membuat Bahan Ajar Inovatif (Yogyakarta: Diva Press, 2011), 16. bahan ajar, membangun komunikasi pembelajaran yang efektif antara guru dengan guru karena siswa akan merasa lebih percaya kepada gurunya, menambah angka kredit jika dikumpulkan menjadi buku dan diterbitkan; 3) manfaatnya bagi siswa yaitu kegiatan pembelajaran menjadi lebih menarik, kesempatan untuk belajar secara mandiri dan mengurangi ketergantungan terhadap kehadiran guru, mendapatkan kemudahan dalam mempelajari setiap kompetensi yang harus dikuasainya.

Sejarah Meneladani Perjuangan Dakwah Rasululla di Madinah

Di kota Madinah, Nabi Muhammad selanjutnya mengatur bangaimana mempersaudarakan para sahabat dari kalangan Anshar dan Muhajiri. Sahabat Anshar adalah sahabat yang berasal dari kalangan Madinah, sedangkan sahabat muhajirin adalah para sahabat yang berhijrah dari kota Mekkah ke kota Madinah atau dengan kata lain sahabat yang berasal dari kota Mekah. Sehingga beberapa sahabat dari kalangan Anshar dan Muhajirin dipersaudarakan secara erat oleh Baginda Nabi Muhammad SAW. Tujuannya adalah untuk mempererat ukhuwah islamiyah. Selain itu juga Baginda Nabi Muhammad SAW menjalin perjanjian dengan kaum Yahudi Madinah supaya mereka tidak mengganggu aktivitas dakwah Islam. Walaupun pada akhirnya kaum Yahudi Madinah juga tetap melanggar perjanjian yang disepakati bersama sebelumnya.

Hal ini juga yang menyebabkan peperangan dan gejolak kesukuan bagi umat muslim Madinah. Beberapa kaum Yahudi Madinah ternyata telah bersekongkol dengan kaum kafir Quraisy untuk menyerang Nabi Muhammad SAW sebab pada saat itu eksistensi agama Islam semakin melesat berkemajuan dan banyak perkembangan. Adapun peperanganpeperangan yang terjadi saat Baginda Nabi Muhammad berada di Madinah ialah sebagai berikut.

1. Perang Badar yang terjadi pada tahun ke-2 Hijrah.

2. Peperangan Uhud yang terjadi pada tahun ke3 Hijrah.

3. Perang Khandaq, yang terjadi pada saat ke-5 Hijrah.

\footnotetext{
${ }^{17}$ Chomsin S Widodo and Jasmadi, Panduan Menyusun Bahan Ajar Berbasis Kompetensi (Jakarta: Elex Media Komputindo, 2008), 32.
} 
4. Perang Hunain yang terjadi pada saat tahun ke-8 Hijrah.

5. Perang Tabuk, terjadi pada tahun ke-9 Hijrah.

Jadi, selama di Madinah, Baginda Nabi Muhammad tidak hanya membentuk tata pemerintahan Islam, akan tetapi juga menjaga stabilitas kota Madinah dari ancaman musuhmusuh dari kalangan kafir Quraisy atau Yahudi.

\section{Hasil dan Pembahasan}

Perolehan data dari tahap awal hingga tahap akhir melalui cara pemberian tes kepada siswa kelas X IPS 1 dan siswa kelas X IPS 2. Adapun siswa kelas X IPS 1 sebagai kelas eksperimen dan siswa kelas X IPS 2 sebagai kelas kontrol. Kelompok eksperimen dalam hal ini ialah siswa kelas X IPS 1 menggunakan bahan ajar berbasis buku cerita, sedangkan siswa kelas X IPS 2 yang tergolong kelompok kontrol menggunakan bahan ajar yang disediakan oleh sekolah. Desain penelitian ini secara sederhana ialah memberi perlakuan kepada siswa keals $\mathrm{X}$ IPS 1 dan tidak memberi perlakuan terhadap siswa kelas X IPS 2. Adapun perlakuan yang diberikan ialah dengan memberikan bahan ajar berbasis buku cerita pada kelas eksperimen dan tidak memberikan perlakuan bahan ajar berbasis buku cerita kepada kelas kontrol.

Bahan ajar berbasis buku cerita yang bermuatan kisah keteladanan para ulama ini mengintegerasikan materi pembelajaran sejarah kebudayaan Islam yakni perjuangan dakwah Rasulullah Saw di Madinah. Materi yang disajikan dalam bahan ajar berbasis buku cerita tersebut mulai dari hijrahnya baginda Nabi ke Madinah, membagun kota Madinah sebagai pusat peradaban Islam dan kepemerintahan, mencetak masyarakat Islam yang mempunyai nilai Islam yang tinggi dan usaha-usaha mempertahankan Islam dari gangguan musuh serta menyebarluaskan agama Islam ke seantero dunia. Adapun spesifikasi bahan ajar berbasis buku cerita ialah a) bahan ajar yang dikembangkan adalah bahan ajar cetak pada materi sejarah meneladani perjuangan dakwah Rasulullah SAW di Madinah; b) pemilihan bahasa yang digunakan dalam bahan ajar ini menggunakan bahasa yang bersahabat dengan peserta didik sehingga mudah dipahami; c) dilengkapi dengan pengetahuan tambahan didalamnya yang akan memperkaya khazanah keilmuan siswa; d) petunjuk penggunaan buku yang menjadi panduan siswa dalam menggunakan bahan ajar berbasis buku cerita; e) soal latihan; f) kunci jawaban; g) refleksi.

Membuka relung hati, mengkritisi sekitar kita dan menerapkan perilaku mulia telah terintegrasi pada materi yang dikemas dengan kisah keteladan para ulama. Setelah mendapatkan data hasil penelitian, selanjutnya dianalisis guna membuat penafsiran terhadap data yang telah dikompilasikan. Dari hasil analisis data tersebut maka dirumuskan untuk menjawab hipotesis penelitian.

Analisis instrumen tes dilakukan dengan cara uji coba instrument tes tahap awal. Hal ini ditujukan untuk mendapatkan nilai siswa sebelum diberikannya tes kepada siswa dalam kelompok kontrol dan kelompok eksperimen guna menghasilkan data penelitian yang akan dianalisis untuk mejawab hipotesis penelitian. Uji coba instrument tes tahap awal diberikan kepada siswa di luar kelompok eksperimen dan kelompok kontrol, yakni pada siswa kelas X IPS 3. Tes yang diuji cobakan pada tahap awal berisi 10 soal. Di mana indikator soal nomor 1 dan 2 ialah siswa dapat mendeteksi salah satu strategi Baginda Nabi Muhammad Saw dalam mewujudkakn keberhasilan dakwah di Madinah. Indikator soal nomor 3,4,6,7 ialah menemukan, menegaskan, serta mendeteksi substansi, strategi, dan keberhasilan dakwah Nabi Muhammad SAW di Madinah. Indikator soal nomor 10 dan 9 ialah menunjukan sikap ukhwah dan kerukunan yang telah dicontohkan oleh Nabi Muhammad Saw di Madinah. Sedangkan indikator soal nomor 8 dan 5 yakni mengidentifikasi tentang beberapa hal yang berhubungan dengan dakwah Nabi Muhammad SAW di Madinah.

Untuk mengetahui validitas instrument tes, teknik analisisnya menggunakan korelasi product moment. Interpretasi validitas instrumen tes melalui cara mengkomprasikan nilai Asymp. Sig. (2-tailed) pada program SPSS dengan taraf 5\% yakni 0,05. Jika perolehan hasil nilai Asymp. Sig (2-tailed) lebih rendah dari 0,05 maka instrument tes berkategori valid. ${ }^{18}$ Diketahui soal nomor 110 dinyatakan valid, karena nilai Sig. (2-tailed) lebih kecil dari 0,05. Hasil analisis data per item soal digambarkan pada tabel berikut.

\footnotetext{
${ }_{18}$ Maswar, Eriyanto, and Junaidi, Teknik. Analisis Dan Regresi; Untuk Penelitian Pendidikan, Ekonomi Dan Bisnis (Surabaya: Pustaka Radja, 2017), 72.
} 


\begin{tabular}{ccc}
\hline $\begin{array}{c}\text { Nomo } \\
\text { r Soal }\end{array}$ & $\begin{array}{c}\text { Probabilita } \\
\text { s Korelasi } \\
\text { [Sig. (2- } \\
\text { tailed)] }\end{array}$ & $\begin{array}{c}\text { Keteranga } \\
\mathbf{n}\end{array}$ \\
\hline 1 & 0,000 & Valid \\
2 & 0,000 & Valid \\
3 & 0,000 & Valid \\
4 & 0,001 & Valid \\
5 & 0,003 & Valid \\
6 & 0,010 & Valid \\
7 & 0,000 & Valid \\
8 & 0,000 & Valid \\
9 & 0,001 & Valid \\
10 & 0,001 & Valid
\end{tabular}

Setelah melakukan uji validitas, selanjutnya ialah uji reliabilitas. Untuk penafsiran reliabilitas adalah dengan cara membandingkan nilai cronbach's alpha, yaitu 0,6. Jika nilai cronbach's alpha lebih besar dari 0,6 maka soal reliabel, namun jika nilai cronbach's alpha lebih kecil dari 0,6 maka soal tidak reliabel. Hasil analisis data nilai cronbach's alpha soal nomor 110 ialah 0,639 lebih besar dari 0,6. Maka soal tersebut dinyatakan reliabel.

\begin{tabular}{crc}
\hline $\begin{array}{c}\text { Cronbach's } \\
\text { Alpha }\end{array}$ & $\begin{array}{c}\text { N } \\
\text { of } \\
\text { Items }\end{array}$ & Keterangan \\
\hline 0,639 & 10 & Reliabel
\end{tabular}

Apabila instrument tes dinyatakan valid dan reliabel, selanjutnya ialah mengetahui nilai siswa dari kelas X IPS 1 dan X IPS 2. Adapun jumlah siswa yang diberi soal sebesar 24 siswa pada kelas X IPS 1 dan 24 siswa pada kelas X IPS 2. Jumlah perolehan nilai pada kelas X IPS 1 ialah 2.240 sedangkan kelas X IPS 2 ialah 1.510. Nilai rata-rata kelas X IPS 1 diketahui sebesar 35,62 sedangkan kelas X IPS 2 diketahui sebesar 13,38. Kelas X IPS 1 mempunyai nilai terendah 80 dan nilai tertinggi 100. Sedangkan kelas X IPS 2 mempunyai nilai terendah sebesar 20 dan nilai tertinggi sebesar 80. Adapun nilai KKM pada kelas X IPS 1 dan X IPS 2 ialah sama-sama 70. Daftar kesimpulan hasil analisis antara kelas X IPS 1 dan kelas X IPS 2 dapat dilihat pada tabel berikut.

\begin{tabular}{cccc}
\hline $\mathbf{N}$ & Indikato & Kela & Kela \\
$\mathbf{0}$ & $\mathrm{r}$ & $\mathrm{s}$ X IPS & $\mathrm{s}$ X IPS \\
& & 1 & 2 \\
\hline
\end{tabular}

${ }^{19}$ Maswar, Eriyanto, and Junaidi, Teknik. Analisis Dan Regresi; Untuk. Penelitian Pendidikan, Ekonomi Dan Bisnis (Surabaya: Pustaka Radja, 2017), 96.

\begin{tabular}{cccc}
\hline 1 & $\begin{array}{c}\text { Jumlah } \\
\text { Siswa }\end{array}$ & 24 & 24 \\
\hline 2 & KKM & 70 & 70 \\
\hline 3 & $\begin{array}{c}\text { Nilai } \\
\text { Terendah }\end{array}$ & 80 & 20 \\
\hline 4 & $\begin{array}{c}\text { Nilai } \\
\text { Tertinggi }\end{array}$ & 100 & 80 \\
\hline 5 & $\begin{array}{c}\text { Jumlah } \\
\text { Nilai }\end{array}$ & 2.240 & 1.510 \\
\hline 6 & $\begin{array}{c}\text { Nilai } \\
\text { Rata-Rata }\end{array}$ & 35,62 & 13,38 \\
& &
\end{tabular}

Untuk mengetahui apakah ada perbedaan hasil belajar yang signifikan antara siswa yang menggunakan bahan ajar berbasis buku cerita dengan siswa yang menggunakan buku paket dari sekolah, maka dilakukan uji mannwhitney. Untuk penafsiran perolehan data mannwhitney adalah jika nilai Asymp. sig. (2-tailed) < 0,05; maka penafsirannya ialah ada perbedaan yang signifikan antara hasil belajar peserta didik kelas X IPS 1 dengan peserta didik kelas X IPS 2. Sebaliknya, jika jika Sig. (2-tailed) > 0,05; maka tidak ada ada perbedaan yang signifikan antara hasil belajar peserta didik kelas X IPS 1 dengan peserta didik kelas X IPS $2 .{ }^{19}$ Perolehan hasil data mann-whitney antara kelas X IPS 1 dan kelas X IPS 2 dapat dilihat pada tabel berikut.

\begin{tabular}{cc}
\hline Indikator & $\begin{array}{c}\text { Hasil Belajar } \\
\text { Sejarah Kebudayaan } \\
\text { Islam }\end{array}$ \\
\hline $\begin{array}{c}\text { Mann- } \\
\text { Whitney U }\end{array}$ & 21,000 \\
\hline Wilcoxon W & 321,000 \\
\hline Z & $-5,662$ \\
\hline $\begin{array}{c}\text { Asymp. Sig. } \\
\text { (2-tailed) }\end{array}$ & 0,000 \\
\hline
\end{tabular}

Dari paparan data pada tabel di atas menunjukan bahwa nilai Asymp. Sig. (2-tailed) ialah 0,000. Hal tersebbut menunjukkan bahwa nilai Asymp. Sig. (2-tailed) lebih kecil dari 0,05. Sehingga kesimpulannya adalah $\mathrm{H}_{\mathrm{o}}$ ditolak dan $\mathrm{H}_{\mathrm{a}}$ diterima. Jadi ada diferensiasi hasil belajar yang signifikan antara kelompok eksperimen yang diberi perlakukan bahan ajar berbasis buku cerita dengan kelompok kontrol yang hanya menggunakan bahan ajar dari sekolah. Sehingga kesimpulannya ialah terdapat pengaruh yang signifikan dari adanya perlakukan bahan ajar 
berbasis buku cerita terhadap prestasi belajar siswa kelas X IPS 1 pada mata pelajaran sejarah kebudayaan Islam tema meneladani perjuangan dakwah Rasulullah Saw di Madinah. Hal tersebut dibuktikan dengan adanya perbedaan yang signifikan antara hasil belajar siswa pada kelas X IPS 1 yang menggunakan buku cerita bahan ajar dengan X IPS 2 yang hanya menggunakan buku paket dari sekolah.

Dari penafsiran perolehan data di atas, bahwa desain bahan ajar yang menarik dapat mempengaruhi pemahaman siswa secara baik yang berupa prestasi belajar. Hal tersebut diperkuat oleh Djamarah bahwa bahan ajar yang dirancang dengan baik dan berintegerasi dengan materi pembelajaran serta gambar yang indah akan memacu motivasi peserta didik guna memakai bahan ajar sebagai sumber belajar serta terdapat kecondongan dari pendidik untuk menyampaikan materi pembelajaran yang tiada tara dengan menjelaskan materi yang relatif mengenai eksperimen dan kehidupan faktual peserta didik sehingga berimplikasi pada totalitas pemahaman materi atau prestasi belajar siswa. ${ }^{20}$

Adanya pengaruh signifikan dari bahan ajar yang telah dikembangkan dengan semenarik mungkin, menandakan bahwa eksistensi bahan ajar sangatlah urgen dalam meningkatkan pemahaman siswa melalui proses pembelajaran. Sebagaimana manfaat bahan ajar yaitu guna menolong guru dalam memberikan isi pembelajaran kepada siswa supaya memahami materi ajar dengan gampang. ${ }^{21}$ Peserta didik dapat belajar tanpa selalu ada ketergantungan dari berbagai pihak apabila bahan ajar didesain dengan sebaik mungkin dan semenarik mungkin. Sebagaimana yang diungkap oleh Pratiwi bahwa bahan ajar mempunyai kegunaan seperti 1) Pedoman bagi guru yang akan melaksanakan rangkaian aktivitas pembelajaan dan memberitahukan kepada peserta didik tentang hakikat materi yang akan dipelajari; 2) Pedoman peserta didik yang akan melaksanakan pembelajaran sebagai subyek aktif dalam mencari

\footnotetext{
${ }^{20}$ Syaiful Bahri Djamarah and Aswan Zain, Strategi Belajar Mengajar (Jakarta: PT Rineka Cipta, 2014), 43.

21 Indri Lestari, "Pengembangan Bahan Ajar Matematika Dengan Memanfaatkan Geogebra Untuk Meningkatkan Pemahaman Konsep," GAUSS: Jurnal Pendidikan Matematika 1, no. 1 (2018): 26, doi:10.30656/gauss.v1i1.634.

22 Sifa Pratiwi, Elsa Komala, and Erma Monariska, "Pengembangan Bahan Ajar Berbasis Cerita Bergambar Matematika," Jurnal Analisa 6, no. 2 (2020): 143-52, doi:10.15575/ja.v6i2.9033.
}

pengetahuan baru, sekaligus merupakan materi pembelajaran yang sepatutnya dipelajari atau dikuasi oleh peserta didik secara mandiri; 3) Menilai ketercapaian materi pembelajaran yang telah diserap oleh peserta didik. ${ }^{22}$

Buku cerita diartikan sebagai rangkaian cerita yang terlukis dalam dunia insan dan benda yang terdapat disekeliling kita, tidak implisit, lebih dominan menggambarkan satu periode dari keadaan seorang insan, dan sering menyentuh pada suatu peristiwa. ${ }^{23}$ Di Indonesia ada beberapa macam buku cerita yang familiar. Diantaranya ialah buku cerita yang terkandung dalam novel. Pada biasanya hamper seluruh novel yang ada pasti bermuatan cerita, sebab tujuan utama dalam buku novel ialah untuk memuaskan para pembaca. Terdapat dua macam novel yakni novel serius dan novel popular. Novel popular seringkali ditujukan pada hal-hal yang bersangkutpaut dengan bisnis, kesenangan orang yang membaca, sehingga novel popular biasanya tidak menjelaskan pada suatu hal yang sifatnya serius sebab yang akan terjadi ialah merosotnya penikmat novel tersebut. Umumnya novel ini relatif gampang dibaca dan tidak susah dipahami karena dalam novel tersebut bermuatan cerita. ${ }^{24}$

Bahan ajar berbasis buku cerita berpengaruh terhadap hasil belajar siswa. Sebagaimana penelitian Zulfah yang berjudul "Pengaruh Buku cerita Kimia Dalam Kegiatan Pembelajaran Terhadap Pemahaman Konsep dan Motivasi Belajar" memberikan kesimpulan bahwa buku cerita kimia yang dikembangkan dengan mengintegerasikan materi pokok hidrokarbon mempunyai pengaruh positif terhadap proses aktivitas belajar siswa memahami materi pembelajaran. ${ }^{25}$ Pada penelitian lain yang dilakukan oleh Lutfiana Khairoh, Ani Rusilowati dan Sri Nurhayati dengan judul "Pengembangan Buku Cerita IPA Terpadu Bermuatan Pendidikan Karakter Peduli Lingkungan Pada Tema Pencemaran Lingkungan" disebutkan bahwa buku cerita Ilmu Pengetahuan Alam Terpadu yang berbasis pendidikan karakter peduli

\footnotetext{
${ }^{23}$ Tim Universitas Gajah Mada, Teori Pengkajian Fiksi (Yogyakarta: Gajah Mada University Press, 2010), 9.

${ }^{24}$ Endang Sri Sulasih, "Pengaruh Minat Membaca Karya Sastra Dan Kreativitas Terhadap Keterampilan Menulis Buku cerita," Pujangga 2, no. 2 (2018): 24, doi:10.47313/pujangga.v2i2.392.

25 Zulfah Zulfah, "Pengaruh Buku cerita Kimia Dalam Kegiatan Pembelajaran Terhadap Pemahaman Konsep Dan Motivasi Belajar," Jurnal Penelitian Dan Pembelajaran IPA 2, no. 2 (2016): 186, doi:10.30870/jppi.v2i2.738.
} 
lingkungan pada tema pencemaran lingkungan sangat layak digunakan sebagai media pembelajaran dan meningkatkan prestasi belajar pemahaman siswa sebesar 0,44 pada kategori sedang. ${ }^{26}$ Arif Rahman Hakim, Saprudin Jauhari dan Nita Sugawa dalam penelitiannya yang berjudul "Pengaruh Bacaan Sastra Anak Terhadap Perkembangan Intelektual Bahasa Siswa Kelas V Sekolah Dasar" juga berkesimpulan bahwa penggunaan bacaan sastra anak mempunyai pengaruh yang signifikan terhadap perkembangan kognitif bahasa siswa. ${ }^{27}$

\section{Simpulan}

Dari uraian pada bagian hasil penelitian dan pembahasan diperoleh data tentang efektivitas bahan ajar berbasis buku cerita pada mata pelajaran sejarah kebudayaan Islam tema meneladani perjuangan dakwah Rasulullah Saw di Madinah melalui uji tes pada kelompok eksperimen yakni kelas X IPS 1 dan kelompok kontrol yakni kelas X IPS 2. Jumlah hasil nilai siswa kelas X IPS 1 ialah 2.240 sedangkan siswa kelas X IPS 2 ialah 1.510. Nilai rata-rata siswa kelas X IPS 1 sebesar 35,62 sedangkan siswa kelas X IPS 2 sebesar 13,38. Kelas X IPS 1 mempunyai nilai terendah 80 dan nilai tertinggi 100 . Sedangkan kelas $\mathrm{X}$ IPS 2 mempunyai nilai terendah 20 dan nilai tertinggi 80 . Data tersebut selanjutnya diolah menggunakan mann-wbitney dengan perolehan nilai Asymp. Sig. (2-tailed) ialah 0,000 . Sehingga interpretasinya ialah terdapat pengaruh yang signifikan dari adanya perlakukan bahan ajar berbasis buku cerita terhadap prestasi belajar siswa kelas X IPS 1 pada mata pelajaran sejarah kebudayaan Islam tema meneladani perjuangan dakwah Rasulullah Saw di Madinah. Jadi, bahan ajar berbasis buku cerita efektif digunakan pada mata pelajaran sejarah kebudayaan Islam tema meneladani perjuangan dakwah Rasulullah Saw di Madinah.

\section{Daftar Rujukan}

Djamarah, Syaiful Bahri, and Aswan Zain. Strategi Belajar Mengajar. Jakarta: PT Rineka Cipta, 2014.

Hakim, Arif Rahman, Saprudin Jauhari, and Nita Sugawa. "Pengaruh Bacaan Sastra Anak Terhadap Perkembangan Intelektual Bahasa Siswa Kelas V Sekolah Dasar." Jurnal Elementary 3, no. 2 (2020): 87-91.

\footnotetext{
26 Lutfiana Khairoh, Ani Rusilowati, and Sri Nurhayati, "Pengembangan Buku Cerita IPA Terpadu Bermuatan Pendidikan Karakter Peduli Lingkungan Pada Tema Pencemaran Lingkungan," Unnes Science Education Journal 3, no. 2 (2014): 519-27, doi:10.15294/usej.v3i2.3349.
}

Handayani, Sri. "Perbandingan Efektifitas Pemberian Informasi Melalui Media Cerita Bergambar (Komik) Versi BKKBN Dengan Media Leaflet." GASTER 7, no. 1 (2010): 482-90.

Khairoh, Lutfiana, Ani Rusilowati, and Sri Nurhayati. "Pengembangan Buku Cerita IPA Terpadu Bermuatan Pendidikan Karakter Peduli Lingkungan Pada Tema Pencemaran Lingkungan." Unnes Science Education Journal 3, no. 2 (2014): 519-27. doi:10.15294/usej.v3i2.3349.

Khoiri, M., and Kusyairi. "Penilaian Bahan Ajar Bahasa Madura Tingkat Sekolah Menengah Atas (SMA)." Jurnal Bahasa, Sastra Indonesia, Dan Pengajarannya 2, no. 2 (2019): 274-85.

Khulsum, Umi, Yusak Hudiyono, and Endang Dwi Sulistyowati. "Pengembangan Bahan Ajar Menulis Cerpen Dengan Media Storyboard Pada Siswa Kelas X SMA." DIGLOSIA : Jurnal Kajian Bahasa, Sastra, Dan Pengajarannya 1, no. 1 (2018): 1-12. doi:10.30872/diglosia.v1i1.pp1-12.

Kurniawati, Fitri Erning. "Pengembangan Bahan Ajar Aqidah Ahklak Di Madrasah Ibtidaiyah." Jurnal Penelitian 9, no. 2 (2015): 367. doi:10.21043/jupe.v9i2.1326.

Lestari, Indri. "Pengembangan Bahan Ajar Matematika Dengan Memanfaatkan Geogebra Untuk Meningkatkan Pemahaman Konsep." GAUSS: Jurnal Pendidikan Matematika 1, no. 1 (2018): 26. doi:10.30656/gauss.v1i1.634.

Maswar, Eriyanto, and Junaidi. Teknik Analisis Dan Regresi; Untuk Penelitian Pendidikan, Ekonomi Dan Bisnis. Surabaya: Pustaka Radja, 2017.

Moh. Nawafil, and Junaidi Junaidi. "Revitalisasi Paradigma Baru Dunia Pembelajaran Yang Membebaskan." Jurnal Pendidikan Islam Indonesia 4, no. 2 (April 15, 2020): 215-25. doi:10.35316/jpii.v4i2.193.

Nurseto, Tejo. "Membuat Media Pembelajaran Yang Menarik." Jurnal Ekonomi \& Pendidikan 8, no. 1 (2011): 19-35.

Praswoto, A. Panduan Kreatif Membuat Bahan Ajar Inovatif. Yogyakarta: Diva Press, 2011.

Pratiwi, Sifa, Elsa Komala, and Erma Monariska. "Pengembangan Bahan Ajar Berbasis Cerita Bergambar Matematika." Jurnal Analisa 6, no. 2 (2020): 143-52.

\footnotetext{
27 Arif Rahman Hakim, Saprudin Jauhari, and Nita Sugawa, "Pengaruh Bacaan Sastra Anak Terhadap Perkembangan Intelektual Bahasa Siswa Kelas V Sekolah Dasar," Jurnal Elementary 3, no. 2 (2020): 87-91.
} 
doi:10.15575/ja.v6i2.9033.

Purwanto, Rati. "Home Visit Method Dalam Upaya Meningkatkan Motivasi Belajar Siswa Sekolah Dasar." Terampil: Jurnal Pendidikan Dan Pembelajaran Dasar 8, no. 1 (2021): 5164.

Sari, Kartika Permata. "Evaluasi Bahan Ajar Bahasa Prancis Le Mag Sebagai Bahan Pembelajaran Mandiri Siswa Sekolah Menengah Atas." Jurnal Inovasi Teknologi Pendidikan 4, no. 2 (2018): 214-26. doi:10.21831/jitp.v4i2.17155.

Sari, Yunita, and Sari Yustiana. "Efektivitas Bahan Ajar Cerita Bergambar Bemuatan Religius Terhadap Prestasi Belajar Siswa Kelas 1 Sekolah Dasar." Jurnal Ilmiah Pendidikan Dasar 8, no. 2 (2021): 175. doi:10.30659/pendas.8.2.175-185.

Shaleh, Muh., and La Ode Anhusadar. "Kesiapan Lembaga PAUD Dalam Pembelajaran Tatap Muka Pada New Normal." Jurnal Obsesi: Jumal Pendidikan Anak Usia Dini 5, no. 2 (2021): 2158-67.

Suardi, M. Belajar Dan Pembelajaran. Yogyakarta: CV Budi Utama, 2015.

Sulasih, Endang Sri. "Pengaruh Minat Membaca Karya Sastra Dan Kreativitas Terhadap Keterampilan Menulis Novel." Pujangga 2, no. 2 (2018): 24. doi:10.47313/pujangga.v2i2.392.

Suparman, M Atwi. Desain Instruksional Modern. Jakarta: Erlangga, 2014.

Tim Universitas Gajah Mada. Teori Pengkejian Fiksi. Yogyakarta: Gajah Mada University Press, 2010.

Widodo, Chomsin S, and Jasmadi. Panduan Menyusun Bahan Ajar Berbasis Kompetensi. Jakarta: Elex Media Komputindo, 2008.

Zulfah, Zulfah. "Pengaruh Novel Kimia Dalam Kegiatan Pembelajaran Terhadap Pemahaman Konsep Dan Motivasi Belajar." Jurnal Penelitian Dan Pembelajaran IPA 2, no. 2 (2016): 186. doi:10.30870/jppi.v2i2.738. 